Research Square
Preprints are preliminary reports that have not undergone peer review.

They should not be considered conclusive, used to inform clinical practice, or referenced by the media as validated information.

\title{
Identifying core competencies for public health professionals in Uttar Pradesh, India: results from a Delphi exercise
}

\section{Sudip Bhandari ( $\nabla$ sudipbhandari@jhu.edu )}

Department of International Health, Johns Hopkins Bloomberg School of Public Health, Baltimore, MD, USA

https://orcid.org/0000-0001-8627-5467

\section{Brian Wahl}

Johns Hopkins University Bloomberg School of Public Health https://orcid.org/0000-0002-0037-7364

\section{Sara Bennett}

Johns Hopkins University Bloomberg School of Public Health

Cyrus $Y$ Engineer

Johns Hopkins University Bloomberg School of Public Health

\section{Pooja Pandey}

State Institute of Health and Family Welfare, Government of Uttar Pradesh

\section{David H Peters}

Johns Hopkins University Bloomberg School of Public Health

\section{Research}

Keywords: Public health competencies, Delphi technique, human resource development, India

Posted Date: March 17th, 2020

DOI: https://doi.org/10.21203/rs.3.rs-17460/v1

License: (c) (i) This work is licensed under a Creative Commons Attribution 4.0 International License. Read Full License 


\section{Abstract}

\section{Background}

Ensuring the public health workforce has appropriate competencies to fulfill essential public health functions is a challenge in many low- and middle-income countries. The absence of an agreed set of core competencies to provide a basis for developing and assessing knowledge, skills, abilities, and attitudes contributes to this challenge. In Uttar Pradesh, India, where most staff are trained as clinicians, this study is aimed at identifying the requisite core competencies for health professionals in mid-level supervisory and program management roles to effectively perform their public health responsibilities.

\section{Methods}

We used a multi-step, interactive Delphi technique to develop an agreed set of public health competencies. A narrative review of core competency frameworks and key informant interviews with human resources for health experts in India were conducted to prepare an initial list of 40 competency statements in eight domains. We then organized a day-long workshop bringing together 22 public health experts and government officials from India, who added to and modified the initial list. After this, a revised list of 54 competency statements was rated on a 5-point Likert scale, with 1 as "not at all important" to 5 as "absolutely essential". Aggregate statement scores were shared with the participants, who discussed the findings. Finally, the same list was returned to participants for an additional round of ratings. Stability between scores at different steps was identified using the Wilcoxon matched-pairs signed-rank test. Consensus was defined using the percent agreement criterion.

\section{Results}

Stability between the first and second Delphi scoring steps was reached in 46 of the 54 statements presented to participants. By the end of the second Delphi scoring step, consensus was reached on 48 competency statements across eight domains: public health sciences, assessment and analysis, policy and program management, financial management and budgeting, partnerships and collaboration, social and cultural determinants, communication, and leadership.

\section{Conclusions}

This study produced a consensus set of core competencies and domains in public health that can be used to review current training practices, assess competencies of public health professionals, and revise or develop new training programs to address desired competencies in Uttar Pradesh. Findings from this study can also be used to support workforce development by informing competency-based job descriptions for recruitment and performance management and adapted for use elsewhere.

\section{Background}

A competent workforce is a prerequisite for a high performing public health system (1-4). However, many low-resource settings, including the state of Uttar Pradesh (UP) in India, struggle to ensure the health workforce has the appropriate public health competencies needed to perform public health functions effectively $(5,6)$.

UP is the largest state in India, with almost 230 million people (7). As with many states in the country, UP continues to face several health workforce challenges. There are currently an estimated 9.1 health workers per 10,000 population compared to the WHO proposed Sustainable Development Goal index threshold of 44.5 health workers per 10,000 (8). There are no requirements for health workers to receive public health training, making it challenging to deliver essential public health functions for population health or professionally manage health services. In addition, there remain challenges related to improving the match between professional competencies and population health priorities, the mix of competencies among the health workforce, and the distribution of professionals across geographical areas-specifically rural and urban areas (9).

The identification of core competencies for public health professionals in UP provides a basis to address some of these challenges. Core competencies are key knowledge, skills, abilities, and attitudes that the health workforce should possess to effectively deliver essential public health functions like epidemiological surveillance, situation assessments, and health 
promotion $(10,11)$. They draw on multiple public health disciplines and are not specific to a single program or topic. Core competencies should be defined for all employees in all positions throughout the public health system. However, competencies may be required at different proficiency levels for different cadres depending on the nature of their job responsibilities.

Around the world, efforts to develop core competencies for public health professionals have largely been made in High-Income Countries (HICs) and regions (12-14), and for the clinical health workforce (15-17), researchers working in low-resource settings (18), and public health academic programs (19-21). In India, the Public Health Foundation of India (PHFI), the Union Ministry of Health and Family Welfare (MOHFW), and others have developed core competencies frameworks for Master's in Public Health (MPH) programs and community medicine fellowships (22-24).

This study builds on these efforts and aims to identify the core competencies for public health professionals in supervisory or program management roles in UP. Currently, there is no public health cadre in the state, so these competencies are intended for professionals who have job responsibilities in public or population health. The identified core competencies are applicable to staff like Medical Officers (MOs), District Program Managers (DPMs), and Additional Chief Medical Officer (ACMO) who are senior to the frontline staff (i.e., ASHAs, Anganwadi workers) and junior to senior management and executive-level staff (i.e., Directors, Additional Directors, Chief Medical Officers) in the UP health system. Examples of responsibilities include developing operational plans to implement national programs, providing assistance in the formulation of village health and sanitation plans, undertaking financial and administrative duties, and organizing in-service training programs for staff in their facilities.

This study was undertaken as a part of broader efforts to strengthen public health worker performance, performance management, and training in the state. These efforts, particularly public health training, are timely given the national emphasis on health promotion and prevention through the creation of Health and Wellness Centers (HWCs) under the Ayushman Bharat program (25). The Indian national health policy (2017) has encouraged states to create a separate public health cadre (26). As UP contemplates developing its public health cadre, core competencies and subsequent training of current health officials can act as a stopgap measure to address current public health deficiencies. These can also inform the formal training that a public health cadre would need.

\section{Methods}

We employed the multi-step interactive Delphi technique called Estimate-Talk-Feedback-Estimate (EFTE), a widely-used consensus generating method that solicits opinions of experts through a series of carefully designed questionnaires and faceto-face discussions $(27,28)$. We used the Delphi technique because of its various advantages including anonymity between participants-which minimizes group discussion biases; iteration with controlled feedback of group opinion-achieved through the use of successive questionnaires allowing participants to amend their views if they want; statistical aggregation of group response-which is shared with the participants, enabling them to see where their opinions lie relative to the group response; and expert input-ensuring that the participants are experts adequately informed in the topic (29).

We followed a total of eight steps in the Delphi technique, as outlined below and in Figure 1.

\section{Generation of an initial list of relevant core competencies}

We prepared an initial list of 40 competency statements across eight public health domains after undergoing a narrative review and synthesis of core competency frameworks globally and rapid qualitative interviews with Indian public health experts (see Supplementary Table 2, Additional File).

For the narrative review and synthesis, we examined the available core competency frameworks from Canada, Europe, New Zealand, Spain, United Kingdom, United States, and the Americas (13,14,30-33)Competencies listed for Indian MPH curriculums by the Public Health Foundation of India (PHFI) and the Ministry of Health and Family Welfare (MoHFW) were also assessed $(22,23)$. 
Rapid qualitative interviews were conducted with six Indian experts to identify context-specific core competencies to consider. Interviewees with knowledge and expertise in the competency identification of health workers and familiar with the UP context were purposively selected. We used a semi-structured interview guide to extract themes related to participants' understanding of public health and essential public health functions, their comprehension about public health competencies, core competencies required of mid-level public health workers to deliver these essential public health functions, and current challenges as well as opportunities to integrate core competencies in workforce development efforts. After this, we reviewed the transcripts of the interviews, determined sections relevant to the research question, inductively developed a coding system, and identified the material in the transcript related to each topic. We then reworked the competency statements to integrate the findings of the interviews.

\section{Organization of a consensus workshop}

We sought to arrive at a set of public health competencies through a consensus-building process that included a wide range of stakeholders, as this would likely increase the prospects of the results being used in workforce development (34). A one-day consensus generation workshop was held in Lucknow, Uttar Pradesh, on 26 July 2019. A diverse group of 22 participants with backgrounds in public health, professional education, and human resources for health representing the Government of UP (GoUP), academia, and public health Non-Governmental Organizations (NGOs) in India participated in the meeting. Table 1 provides the demographic characteristics of the participants.

Table 1 Demographic characteristics of the Delphi participants $(N=22)$

\begin{tabular}{llll} 
& & Number & Percentage \\
\hline Gender & Male & 19 & $86 \%$ \\
\hline \multirow{2}{*}{ Current role } & Female & 3 & $14 \%$ \\
\hline & Academic & 6 & $27 \%$ \\
\hline & State trainer[1] & 4 & $18 \%$ \\
\hline & Senior manager in government & 9 & $41 \%$ \\
\hline \multirow{2}{*}{ Professional location } & Other (e.g., public health NGO) & 3 & $14 \%$ \\
\hline & Within Uttar Pradesh & 16 & $72 \%$ \\
\hline & Outside of Uttar Pradesh & 6 & $28 \%$
\end{tabular}

[1] State trainers are the faculty members of the State Institute of Health and Family Welfare. One of their primary responsibilities is to train the newly inducted Medical Officers in the public system on public health topics.

At the beginning of the Delphi process in the workshop, the lead author provided detailed background information to the participants about core competencies and the Delphi process to be used in making opinion judgments, and resolved any questions that participants had.

\section{Revision and addition to the initial list}

The 22 participants were divided into four separate groups, with approximately 6 participants per group. These groups were determined before the workshop to ensure heterogeneity of backgrounds among participants in each group.

A list of the initial 40 draft competencies (prepared in step 1) was given to each participant, who then modified and added to the list individually. Participants were asked to focus on amending the list in light of the critical competencies that they thought were necessary to work successfully as a public health program manager or supervisor in UP. In their groups, participants then discussed major changes and additions to the competency list. However, discussion regarding weights or importance of competency statements was discouraged to avoid groupthink and interfere with the goals of the process. 
The Delphi facilitators in each group (each with graduate training in public health, who were provided training specific to Delphi facilitation) consolidated the written amendments from the participants to decrease duplication and sought clarifications on competency phrasing if required. The facilitators then worked across groups to compile the list of additions and modifications to develop an updated competency list, which included 54 competency statements.

\section{First Delphi scoring}

This modified list of competency statements was presented to all 22 participants. They individually rated each of the 54 competency statements in terms of their importance on a five-point Likert scale, from 1 as "not at all important" to 5 as "absolutely essential." Participants then scored each statement on its own merit instead of comparing it against the other proposed competencies. They were encouraged to score based on how important they thought the competency is to provide public health services as a mid-level public health manager in UP currently.

\section{Score compilation, analysis, and summarization}

The questionnaire results from step 5 were compiled, analyzed, and summarized. Results were shared with individual groups and displayed to the panel. Competency statements were ranked from high (absolutely essential) to low (not at all important). Averages, median, and quartiles were shared with the participants to facilitate the discussion.

\section{Discussion of results}

Participants discussed the results of at least two domains pre-assigned to their groups. Delphi facilitators guided the discussions, and participants were allowed to question findings and suggest alternatives. Each group then reported back to the plenary on the main points from their discussions.

\section{Second Delphi scoring}

The same competency list was returned to the 19 remaining participants who were asked to rate these statements again.

\section{Data analysis}

After the workshop, the stability between Delphi scoring steps (steps 5 and 8 listed above) was assessed using Wilcoxon matched-pairs signed-rank test. Previous research shows that it is necessary to ensure that there is enough stability between Delphi scoring rounds to establish that the results are stable and reliable (35). A statement was considered stable if there was no statistically significant change in responses between the scoring steps for each statement $(p \geq 0.05)$.

Consensus was identified using the percent agreement criterion. A statement was deemed to have reached consensus when over $80 \%$ of the participants ranked it as "very important $=4$ " or "absolutely essential $=5$ " in the second Delphi scoring step (step 8).

Data from the two Delphi scoring steps were entered into STATA 14.2 and analyzed (36). For both the scoring steps, the measures of central tendency (mean, median, and mode) and measures of dispersion (range, interquartile range, and standard deviation) were also calculated.

\section{Results}

\section{Findings from the narrative review: International scenario of core competencies for public health professionals}

Based on the narrative review, we found similarities in domains and competencies across various core competency frameworks, as well as differences in their emphasis (see Supplementary Table 1, Additional File). Most of the frameworks highlight the 
importance of utilizing public health assessment and analysis tools, using communication competencies to improve health outcomes and reduce health inequalities, and translating public health sciences into practice. However, there are also variations and different emphases. For example, New Zealand uniquely specifies competencies related to the knowledge, understanding, and use of culturally appropriate approaches while working with their indigenous population of Maori (33). On the other hand, the European framework outlines the competency on knowledge and understanding of the genetic factors that affect health outcomes following exposure to environmental hazards (14).

In reviewing the similarities and differences across the frameworks, we merged domains and competencies that were similar, and selected dissimilar ones that we deemed valuable in the UP context to be considered by the Delphi participants. We also reviewed Indian MPH core competency frameworks that have been proposed by PHFI and MOHFW, which identify 86 and 20 core competencies, respectively.

\section{Findings from the Key Informant Interviews}

Respondents underscored the importance of a variety of competencies, including those related to management. They discussed the significance of financial and human resource management, including the active supervision of teams. Given its highlighted importance, we separated management as two domains in the initial competency list-one that focused on policy and program management and the other on financial management and budgeting.

Assessment and analysis skills were also highlighted as important competency areas. Respondents highlighted skills in computing and situation analysis of environmental factors like floods and epidemics, which impact the functioning of the health units. They also discussed communication as another critical competency, which related to the ability of health workers to use interpersonal skills while working with the community and patients. Findings on these areas were incorporated in the initial list of competencies by either expanding on or retaining competency items from the analytical and assessment, and communication domains. The initial list of domains and competencies prepared after the narrative review and key informant interviews is in Appendix 2.

\section{Findings from the Delphi workshop}

Several changes were proposed in step 3-revision and addition to the initial list. Fourteen new competencies were added. See Table 2 for these additions and amendments, which formed the subsequent competency list that participants rated in the Delphi scoring rounds.

Public health sciences domain saw two new competencies added-one on the ability to demonstrate action related to community need assessment, and the other on applying knowledge of public health tools and techniques. In the assessment and analysis domain, a competency about the assessment of the accuracy and importance of data for public health decision making was added. The policy and program management domain saw the addition of five new competencies: on the ability to undertake supply chain and logistics management, demonstration of awareness and coordination skills of policies across different sectors, supporting learning within the organization, leveraging technology to innovate and improvise, and the ability to manage time appropriately. The financial management and budgeting domain had one addition related to the use of financial and accounting techniques for budgeting, procurement, staffing, accounting, and expenditure tracking. Participants added two new competencies in the partnerships and collaboration domain-one on determining benefits of the partnership with different actors and another related to being able to listen, engage, and mobilize communities. Participants added three new competencies-knowledge about leadership styles, identifying the need for change and managing such change, and maintaining organizational justice as well as fairness in dealing with subordinates-in the leadership domain.

Stability between the two steps of Delphi scoring was reached in 46 of the 54 statements presented to the participants. Eight statements where stability was not reached $(p<0.05)$ are identified in Table 2 with a red highlight in the corresponding $p$-value. Given their importance - determined by percent agreement criterion-we included seven of them on our final list. The remaining one item did not meet the consensus agreement criterion and was removed from the final list. By the end of the third round, consensus was reached on 48 competency statements across eight domains: (1) public health sciences, (2) assessment and 
analysis, (3) policy and program management, (4) financial management and budgeting, (5) partnerships and collaboration, (6) social and cultural determinants, (7) communication, and (8) leadership. Six items that did not reach consensus were removed from the final list. Results from the Delphi scoring steps, including the median and proportion consensus for each competency statement, are summarized in Table 2. 


\begin{tabular}{|c|c|c|c|c|c|c|c|c|}
\hline \multirow[t]{2}{*}{ Domain } & \multirow{2}{*}{ List of competencies } & \multicolumn{3}{|c|}{ First Delphi scoring } & \multicolumn{3}{|c|}{ Second Delphi scoring } & \multirow[b]{2}{*}{$\begin{array}{l}\text { Stability: } \\
\text { (p- } \\
\text { value) } \\
{[4]}\end{array}$} \\
\hline & & $\mathbf{N}$ & Median & $\begin{array}{c}\% \\
\text { Consensus } \\
(>3)\end{array}$ & $\begin{array}{c}\mathbf{N} \\
{[2]}\end{array}$ & Median & $\begin{array}{l}\% \\
\text { Consensus } \\
{[3]_{(>3)}}\end{array}$ & \\
\hline \multirow[t]{6}{*}{$\begin{array}{l}\text { 1. Public health } \\
\text { sciences }\end{array}$} & $\begin{array}{l}\text { 1.01 Demonstrate knowledge about the } \\
\text { following concepts: the health status of } \\
\text { populations, inequities in health, the } \\
\text { determinants of health and illness, strategies } \\
\text { for health promotion, disease and injury } \\
\text { prevention and health protection, as well as the } \\
\text { factors that influence the delivery and use of } \\
\text { health services. }\end{array}$ & 22 & 5 & 95.45 & 19 & 5 & 100.00 & 0.15 \\
\hline & $\begin{array}{l}\text { 1.02 Demonstrate knowledge about the history, } \\
\text { structure, and interaction of public health and } \\
\text { health care services at local, district, state, } \\
\text { national, and international levels. }\end{array}$ & 22 & 4 & 54.55 & 19 & 4 & 78.95 & 0.03 \\
\hline & $\begin{array}{l}1.03 \text { Apply the public health sciences (e.g., } \\
\text { behavioral and social sciences, biostatistics, } \\
\text { economics, epidemiology, environmental public } \\
\text { health, demography) to practice including } \\
\text { relationships between health and poverty and } \\
\text { other forms of disadvantage. }\end{array}$ & 22 & 4 & 77.27 & 19 & 4 & 100.00 & 0.11 \\
\hline & $\begin{array}{l}1.04 \text { Use evidence and research to inform } \\
\text { health policies and programs. }\end{array}$ & 22 & 4 & 68.18 & 19 & 4 & 84.21 & 0.05 \\
\hline & $\begin{array}{l}\text { 1.05 Demonstrate fundamental action to } \\
\text { undertake community need assessment. }\end{array}$ & 22 & 4.5 & 86.36 & 19 & 4 & 89.47 & 0.97 \\
\hline & $\begin{array}{l}1.06 \text { Apply knowledge of public health tools and } \\
\text { technique. }\end{array}$ & 22 & 4.5 & 86.36 & 19 & 5 & 84.21 & 0.65 \\
\hline \multirow[t]{6}{*}{$\begin{array}{l}\text { 2. Assessment } \\
\text { and Analysis }\end{array}$} & $\begin{array}{l}2.01 \text { Identify relevant and appropriate sources } \\
\text { of information, including community resources. }\end{array}$ & 22 & 4 & 90.91 & 19 & 5 & 100.00 & 0.03 \\
\hline & $\begin{array}{l}2.02 \text { Collect, store, retrieve, and use accurate } \\
\text { and appropriate data on public health issues. }\end{array}$ & 22 & 5 & 72.73 & 19 & 5 & 84.21 & 0.03 \\
\hline & $\begin{array}{l}2.03 \text { Analyze information to determine } \\
\text { appropriate implications, uses, gaps, and } \\
\text { limitations. }\end{array}$ & 22 & 5 & 81.82 & 19 & 5 & 89.47 & 0.26 \\
\hline & $\begin{array}{l}\text { 2.04 Determine the meaning of information, } \\
\text { considering the current ethical, political, } \\
\text { scientific, socio-cultural and, economic } \\
\text { contexts. }\end{array}$ & 22 & 4 & 72.73 & 19 & 4 & 78.95 & 0.91 \\
\hline & $\begin{array}{l}2.05 \text { Recommend specific actions based on the } \\
\text { analysis of information. }\end{array}$ & 21 & 5 & 90.48 & 19 & 5 & 94.74 & 0.09 \\
\hline & $\begin{array}{l}\text { 2.06 Assess the accuracy and importance of } \\
\text { data for public health decision making. }\end{array}$ & 22 & 5 & 100.00 & 19 & 5 & 100.00 & 0.10 \\
\hline \multirow[t]{8}{*}{$\begin{array}{l}\text { 3. Policy and } \\
\text { Program } \\
\text { Management }\end{array}$} & $\begin{array}{l}\text { 3.01 Describe selected policy and program } \\
\text { options to address a specific public health } \\
\text { issue. }\end{array}$ & 22 & 4 & 72.73 & 19 & 5 & 94.74 & 0.09 \\
\hline & $\begin{array}{l}\text { 3.02 Describe the implications of each option, } \\
\text { especially as they apply to the determinants of } \\
\text { health, and recommend or decide on a course } \\
\text { of action. }\end{array}$ & 22 & 4 & 77.27 & 19 & 4 & 84.21 & 0.56 \\
\hline & $\begin{array}{l}\text { 3.03 Develop a plan to implement a course of } \\
\text { action, taking into account relevant evidence, } \\
\text { emergency planning procedures, regulations } \\
\text { and policies, and legislation (e.g., government } \\
\text { order). }\end{array}$ & 22 & 5 & 95.45 & 19 & 5 & 100.00 & 0.93 \\
\hline & $\begin{array}{l}\text { 3.04 Take appropriate action to address a } \\
\text { specific public health issue. }\end{array}$ & 21 & 5 & 100.00 & 19 & 5 & 94.74 & 0.48 \\
\hline & $\begin{array}{l}\text { 3.05 Implement a policy, program, or effective } \\
\text { practice guidelines (e.g., immunization } \\
\text { guidelines, screening programs for illnesses, } \\
\text { etc.), including the allocation of personnel, } \\
\text { financial, and other resources. }\end{array}$ & 22 & 5 & 100.00 & 19 & 5 & 100.00 & 0.18 \\
\hline & $\begin{array}{l}\text { 3.06 Monitor and evaluate an action, policy, or } \\
\text { program. }\end{array}$ & 22 & 5 & 100.00 & 19 & 5 & 100.00 & 0.74 \\
\hline & $\begin{array}{l}\text { 3.07 Demonstrate the ability to fulfill functional } \\
\text { roles in response to a public health emergency. }\end{array}$ & 22 & 4.5 & 81.82 & 19 & 4 & 94.74 & 0.68 \\
\hline & $\begin{array}{l}\text { 3.08 Establish teams for the purpose of } \\
\text { achieving program and organizational goals }\end{array}$ & 22 & 4.5 & 95.45 & 19 & 5 & 94.74 & 0.93 \\
\hline
\end{tabular}


4. Financial

Management and Budgeting
5. Partnerships and

Collaboration

6. Social and

Cultural

Determinants

7.

Communication (e.g., considering the value of different disciplines, sectors, skills, experiences, and perspectives; determining the scope of work and timeline).

3.09 Motivate and supervise personnel for the purpose of achieving program and organizational goals (e.g., participating in teams, encouraging sharing of ideas, respecting different points of view).

3.10 Use evaluation and data to improve health systems, programs, and organizational performance.

3.11 Undertake supply chain and logistics management, including inventory control. ${ }^{*}$

3.12 Demonstrate awareness of policies across different sectors and coordinate across sectors. 3.13 Support learning within an organization including on-the-job learning.

3.14 Leverage technology to innovate, understand, apply, and evaluate/improvise.

3.15 Be able to manage time appropriately. 4.01 Justify programs for inclusion in budgets, develop and defends budgets.

4.02 Prepare proposals for funding (e.g., foundations, government agencies, corporations).

4.03 Use financial analysis methods in making decisions about policies, programs, and services (e.g., economic analyses).

4.04 Manage programs within current and projected budgets and staffing levels (e.g., sustaining a program when funding and staff are cut, recruiting and retaining staff).

4.05 Use financial and accounting techniques for budgeting, procurement, staffing,

accounting, and expenditure tracking.

5.01 Identify and collaborate with partners in addressing public health issues.

5.02 Use skills such as team building, negotiation, conflict management, and group facilitation to build partnerships.

5.03 Mediate between differing interests in the pursuit of health and well-being ("and facilitate the allocation of resources"-deleted in second Delphi scoring).

5.04 Determine benefits of the partnership with different actors to make strategic partnership choices. $^{*}$

$5.05 \mathrm{Be}$ able to listen, engage, and mobilize communities.

6.01 Recognize how the determinants of health (biological, social, cultural, economic, and physical) influence the health and well-being of specific population groups.

6.02 Address population diversity when planning, implementing, adapting, and evaluating public health programs and policies. 6.03 Apply culturally-relevant and appropriate approaches with people from diverse castes, religions, socioeconomic and educational backgrounds, and persons of all ages, genders, health status, sexual orientations, and abilities. 7.01 Listen and communicate effectively with individuals, families, groups, communities, and colleagues, including supervisors and team members.

7.02 Interpret information for professional,

\begin{tabular}{|c|c|c|c|c|c|c|}
\hline 22 & 5 & 95.45 & 19 & 5 & 94.74 & 0.67 \\
\hline 22 & 5 & 86.36 & 19 & 5 & 100.00 & 0.50 \\
\hline 22 & 4 & 77.27 & 19 & 4 & 78.95 & 0.67 \\
\hline 21 & 4 & 71.43 & 19 & 4 & 78.95 & 0.62 \\
\hline 22 & 4 & 77.27 & 19 & 4 & 89.47 & 0.03 \\
\hline 22 & 4 & 68.18 & 19 & 5 & 89.47 & 0.06 \\
\hline 22 & 4 & 81.82 & 19 & 5 & 84.21 & 0.29 \\
\hline 22 & 4.5 & 81.82 & 19 & 5 & 89.47 & 0.31 \\
\hline 22 & 4 & 72.73 & 19 & 4 & 84.21 & 0.49 \\
\hline 22 & 4 & 90.91 & 19 & 5 & 84.21 & 0.32 \\
\hline 22 & 4.5 & 95.45 & 19 & 5 & 100.00 & 0.14 \\
\hline 22 & 5 & 95.45 & 19 & 5 & 100.00 & 0.24 \\
\hline 21 & 4 & 85.71 & 19 & 5 & 94.74 & 0.65 \\
\hline$\overline{21}$ & 5 & $\begin{array}{l}95.24 \\
\end{array}$ & 19 & 5 & 94.74 & 0.91 \\
\hline 22 & 4 & 68.18 & 19 & 4 & 84.21 & 0.10 \\
\hline 22 & 4 & 72.73 & 19 & 4 & 73.68 & 0.63 \\
\hline 20 & 4 & 75.00 & 19 & 4 & 89.47 & 0.32 \\
\hline$\overline{22}$ & 4 & $\begin{array}{l}81.82 \\
\end{array}$ & 19 & 5 & $\begin{array}{l}94.74 \\
\end{array}$ & 0.19 \\
\hline$\overline{22}$ & 4 & 90.91 & 19 & 5 & 89.47 & 0.07 \\
\hline 22 & 4 & 86.36 & 19 & 4 & 89.47 & 0.29 \\
\hline 22 & 5 & 100.00 & 19 & 5 & 100.00 & 0.16 \\
\hline 22 & 4 & 81.82 & 19 & 5 & 89.47 & 0.03 \\
\hline
\end{tabular}

Page 9/16 


\begin{tabular}{|c|c|c|c|c|c|c|c|c|}
\hline & \multicolumn{8}{|l|}{ nonprofessional, and community audiences. } \\
\hline & $\begin{array}{l}7.03 \text { Mobilize individuals and communities by } \\
\text { using appropriate media, community resources, } \\
\text { and social marketing techniques. }\end{array}$ & 22 & 4 & 86.36 & 19 & 4 & 94.74 & 0.26 \\
\hline & $\begin{array}{l}7.04 \text { Use current technology to communicate } \\
\text { effectively. }\end{array}$ & 22 & 4 & 100.00 & 19 & 5 & 94.74 & 0.39 \\
\hline & $\begin{array}{l}\text { 7.05 Advocate and network for healthy public } \\
\text { policies and services that promote and protect } \\
\text { the health and well-being of individuals and } \\
\text { communities. }\end{array}$ & 22 & 4 & 81.82 & 19 & 4 & 89.47 & 0.45 \\
\hline \multirow[t]{9}{*}{ 8. Leadership } & $\begin{array}{l}\text { 8.01 Describe the mission and priorities of the } \\
\text { public health organization where one works } \\
\text { and apply them in practice. }\end{array}$ & 22 & 4 & 81.82 & 19 & 5 & 100.00 & 0.01 \\
\hline & $\begin{array}{l}\text { 8.02 Contribute to developing key values and a } \\
\text { shared vision in planning and implementing } \\
\text { public health programs and policies in the } \\
\text { community. }\end{array}$ & 22 & 4 & 86.36 & 19 & 5 & 100.00 & 0.04 \\
\hline & $\begin{array}{l}\text { 8.03 Utilize public health ethics to manage self, } \\
\text { others, information, and resources. }\end{array}$ & 22 & 4.5 & 81.82 & 19 & 5 & 94.74 & 0.02 \\
\hline & $\begin{array}{l}\text { 8.04 Contribute to team and organizational } \\
\text { learning in order to advance public health } \\
\text { goals. }\end{array}$ & 21 & 4 & 90.48 & 19 & 5 & 100.00 & 0.47 \\
\hline & $\begin{array}{l}8.05 \text { Contribute to maintaining organizational } \\
\text { performance standards. }\end{array}$ & 22 & 4 & 90.91 & 19 & 4 & 100.00 & 0.56 \\
\hline & $\begin{array}{l}\text { 8.06 Demonstrate an ability to build community } \\
\text { capacity by sharing knowledge, tools, } \\
\text { expertise, and experience. }\end{array}$ & 22 & 4 & 77.27 & 19 & 5 & 94.74 & 0.11 \\
\hline & $\begin{array}{l}\text { 8.07 Demonstrate knowledge about different } \\
\text { leadership styles, traits, etc. }\end{array}$ & 22 & 4 & 72.73 & 19 & 4 & 68.42 & 0.65 \\
\hline & $\begin{array}{l}8.08 \text { Identify a need for change, manage } \\
\text { change and processes. }\end{array}$ & 22 & 4.5 & 72.73 & 19 & 4 & 94.74 & 0.55 \\
\hline & $\begin{array}{l}\text { 8.09 Maintain organizational justice, equality, } \\
\text { and fairness in dealing with subordinates. }\end{array}$ & 22 & 5 & 77.27 & 18 & 5 & 100.00 & 0.60 \\
\hline
\end{tabular}

[1] [2]

Bolded statements compose the final list of competencies.

Step 8 (second round of Delphi scoring) had three fewer participants compared to Step 5 (first round of scoring). All three participants who left were male, two of whom were government human resource planner, and one was an academic. Note: participants are the same people in each step, as no new participants were added between steps.

[3]

Consensus was identified using percent agreement criterion. A statement was deemed to have reached consensus when over $80 \%$ of the participants ranked it as "very important=4" or "absolutely essential=5" in the second Delphi scoring step. The statements where no consensus was reached have been identified in the table above with a red text in the corresponding p-value.

[4]

St Stability between Delphi scoring steps was assessed using Wilcoxon matched-pairs signed-rank test. We considered a statement to be stable if there was no statistically significant change in responses between the scoring steps for each statement ( $p \geq 0.05)$. Statements where stability was not reached $(p<0.05)$ have also been identified in red text in the table above. Given the importance of these competencies, we left them on our final list. We recognize that subsequent Delphi steps to generate stability in these statements would have been ideal.

* Competency statement was added in step 3-revision and addition of the list.

\section{Discussion}

We generated expert consensus on core competencies for public health professionals assuming mid-level management roles in Uttar Pradesh, India, using an interactive Delphi technique. Consensus was achieved on 48 competencies across eight domains in public health. These competencies represent the current requirements of health professionals to fulfill their job roles and to address the public health needs of UP.

To our knowledge, this is the first attempt to develop core competencies for practicing public health professionals in UP or elsewhere in India. There have been previous efforts in India to generate core competencies in public health education. However, an attempt to identify practice competencies in UP, and India more broadly, is novel. It is helpful to recognize the distinction between core competencies for public health professionals and those for students in educational programs. Educational competencies tend to delineate the skills, knowledge, abilities, and attitudes that students are expected to achieve at the end of 
their academic programs. They may be organized around traditional academic disciplines like biostatistics, epidemiology, health policy and management, environmental health, and social and behavioral sciences. Professional competencies, on the other hand, reflect the current needs of the workforce, and these are considered to be at the foundation of individual and team success in the workplace (37).

The core competency framework developed in this study covers many of the competencies and domains identified in HICs. However, it also differs in its emphasis on policy and program management, as evident by the number and variety of competencies in this domain. Frameworks from HICs tend to emphasize analysis, assessment, and public health sciences. This difference may reflect the focus of the roles that public health professionals are expected to fulfill in resource-constrained settings like UP. Given health systems challenges like lack of access to essential services, overcrowding of clinics, and medicine shortages, there might be an expectation of public health professionals to possess competencies to manage programs in a resource-constrained environment. This distinction may also reflect the weaknesses of health systems in resource-poor settings, and the need to train public health professionals in management-a vital lever to strengthening health systems (38).

There were six competencies-which belonged to public health sciences, assessment and analysis, policy and program management, partnerships and collaboration, and leadership domains-that did not achieve consensus in the second Delphi round and were removed from the final list. The removed statements are similar in that they focus on demonstrating knowledge rather than skills and their application, on which many of the statements that achieved consensus focused. For example, statements related to demonstrating knowledge about the history and structure of health services, determining the meaning of information, demonstrating awareness of policies, and demonstrating knowledge about leadership styles did not reach consensus. Such lack of consensus could be attributed to the fact that the final list of competencies is meant for practitioners who are expected to apply competencies in their jobs, rather than possess knowledge alone. On the other hand, the final list of competencies could have risen to the top because they represent the skills, knowledge, abilities, and attitudes necessary or expected of public health professionals in UP.

This study has two significant limitations. The first limitation relates to the starting point for core competencies vis-à-vis essential public health functions or job descriptions. In UP, there is no consensus set of Essential Public Health Functions (EPHFs). Usually, the core competencies map to these EPHFs, which is a set of services that underline the activities that public health workers should perform. In the absence of delineated EPHFs, one could use health workers' job descriptions as the starting point for core competencies. However, there were challenges associated even with job descriptions. Job descriptions for some mid-level health professionals are either non-existent (e.g., Deputy Chief Medical Officer, district public health nursing officer) or too generic. Also, there might be a high degree of task variation for the same position across the state. So, we depended on the Delphi participants' expertise to define and interpret health workers' responsibilities.

The second limitation relates to the use of the Delphi technique, which has numerous variations in how it is operationalized. Such variations have left the technique open to methodological interpretations and criticisms $(39,40)$. For this study, the cutoff point of $80 \%$, stability criteria, and the composition of the expert panel were particularly relevant. In terms of the cutoff point, $80 \%$ or higher was chosen a priori because this threshold is common in many Delphi studies (41). However, the theoretical basis for such cutoff is unexplored (39). In terms of analysis, there were a few statements that did not meet the stability criteria, as indicated in Table 2. It would have been ideal to conduct subsequent Delphi scoring steps to attempt to generate stability in these statements as well. However, given the time limitation, we were unable to do so.

Regarding the composition of the expert panel, panelists for this study were chosen after extensive consultations and online searches. However, some potential participants declined the invitation due to a lack of availability. These non-participants were similar in their backgrounds from the participants in the Delphi process. However, a different composition of Delphi participants may have resulted in a different final set of competency statements, as experts panels largely dictate the nature and content of the results in Delphi studies (29).

\section{Conclusions}


The core competencies identified with this research provide a unique starting point in UP to understand and meet health workforce development needs, manage performance, and advance the health of the communities they serve.

Specifically, the results can be used in the following ways. First, core competencies can be codified through a Government Order (GO), which will formalize the findings for government officials and help link future GoUP efforts in performance management to these competencies. Second, the results of this study can be used to develop a competency assessment instrument. Future research can assess the reliability and validity of that instrument, which can then be used to evaluate levels of competencies of health professionals working in management and supervisory roles in UP (42). The results of the assessment can inform appropriate training programs to address gaps in competencies. Third, these results can be used to evaluate training programs offered through the State Institute of Health and Family Welfare (SIHFW) and National Health Mission (NHM) to ascertain their ability to meet the competencies expected of health professionals like Medical Officers (MOs). Based on the findings of the training evaluations, we can improve training programs in the state of UP by collaborating with relevant stakeholders. This may entail a revision of the training modules through consultation with curriculum designers and trainers in UP and the development of cadre-specific training modules. And last, the findings can be used to map the core competencies with the current job descriptions of various health cadres to identify gaps across domains in knowledge, skills, abilities, and attitudes. The results of the mapping process can be used to amend the job descriptions and make them competency based. Competency-based job descriptions will assist in recruitment efforts like screening and interviewing, and to define Key Results Areas (KRAs) to ultimately enable fair and effective performance management systems.

\section{List Of Abbreviations}

EFTE: Estimate-Feedback-Talk-Estimate

EPHFs: Essential Public Health Functions

GO: Government Order

GoUP: Government of Uttar Pradesh

HIC: High-Income Country

MoHFW: Ministry of Health and Family Welfare

MO: Medical Officer

MPH: Master's in Public Health

LMICs: Low- and Middle- Income Countries

UP: Uttar Pradesh

\section{Declarations}

\section{Ethics approval and consent to participate}

Ethical approval for the project was provided by Johns Hopkins Bloomberg School of Public Health Institutional Review Board (IRB No: 00009035).

\section{Consent for publication}

Not applicable.

Availability of data and materials

Page 12/16 
The supplementary tables supporting the conclusions of this article are included in its additional file. The data used and analyzed during the study are available from the corresponding author on reasonable request.

\section{Competing interests}

The authors declare that they have no competing interests.

\section{Funding}

The project under which this study was conducted was supported by the Bill and Melinda Gates Foundation.

\section{Authors' contributions}

BW, SaB, CYE, and DHP contributed to the conception and design of the study, facilitated data acquisition, and provided critical feedback and edits to drafts of the paper. PP offered strategic and technical support to the study. SuB contributed to the data acquisition and analysis, drafted the publication, and managed subsequent revisions. All authors read and approved the final manuscript.

\section{Acknowledgements}

The study investigators would to thank colleagues from Johns Hopkins Bloomberg School of Public Health who assumed the role of Delphi facilitators during the workshop: Binita Adhikari, Shreya Hariyani, Mariana Hernandez, Nidhi Gupta, Ankita Meghani, and Swati Srivastava. The investigators would also like to acknowledge all faculty from the State Institute of Health and Family Welfare for their technical support in this study.

\section{References}

1. Working together for health. Geneva: World Health Organisation; 2006.

2. World Health Organization. Health Systems: Improving Performance, The World Health Report 2000 [Internet]. 2000. Available from: http://www.who.int/whr/2000/en/whr00_en.pdf

3. Peters DH, Chakraborty S, Mahapatra P, Steinhardt L. Job satisfaction and motivation of health workers in public and private sectors: cross-sectional analysis from two Indian states. Human Resources for Health. 2010;

4. Willis-Shattuck M, Bidwell P, Thomas S, Wyness L, Blaauw D, Ditlopo P. Motivation and retention of health workers in developing countries: a systematic review. BMC Health Services Research BMC Health Services Research BMC Health Services Research. 2008;8(8).

5. Frenk J, Chen L, Bhutta Z qar A, Cohen J, Crisp N, Evans T, et al. Health professionals for a new century: transforming education to strengthen health systems in an interdependent world. The Lancet. 2010;376:1923-58.

6. Rao M, Rao KD, Kumar S, Chatterjee M, Sundararaman T. Human resources for health in India. The Lancet. 2011;377:58798.

7. Ministry of Home Affairs, Government of India. Projected Total Population by sex as on 1st March-2001-2026 India, States and Union Territories [Internet]. [cited 2019 Dec 13]. Available from:

http://censusindia.gov.in/Census_Data_2001/Projected_Population/Projected_Population.pdf

8. Health workforce requirements for universal health coverage and the Sustainable Development Goals - Background paper N.1 to the WHO Global Strategy on Human Resources for Health: Workforce 2030 [Internet]. World Health Organization; 2016. Available from: https://apps.who.int/iris/bitstream/handle/10665/250330/9789241511407-eng.pdf? sequence=1

9. Global Health Workforce Alliance and WHO. Scaling Up, Saving Lives [Internet]. 2008. Available from: http://www.who.int/workforcealliance/knowledge/resources/scalingup/en/

10. Public Health Foundation. Competency Assessments for Public Health Professionals [Internet]. 2014. Available from: http://www.phf.org/resourcestools/Pages/Competency_Assessments_For_Public_Health_Professionals.aspx

Page $13 / 16$ 
11. World Health Organization. Essential Public Health Functions, Health Systems, and Health Security [Internet]. 2018. Available from: https://extranet.who.int/sph/sites/default/files/document-library/document/WHO\%20EPHFHealth\%20Security-compressed.pdf

12. Public Health Agency of Canada, Workforce Development Division. Core competencies for public health in Canada [Internet]. Ottawa: Public Health Agency of Canada; 2008. Available from: http://www.phac-aspc.gc.ca/php-psp/ccphcesp/pdfs/cc-manual-eng090407.pdf

13. The Council on Linkages. Core Competencies for Public Health Professionals [Internet]. 2014. Available from: http://www.phf.org/resourcestools/Documents/Core_Competencies_for_Public_Health_Professionals_2014June.pdf

14. ASPHER's European List of Core Competences for the Public Health Professional [Internet]. 2018 [cited 2019 May 14] p. 152. Available from: https://doi.org/10.1177/1403494818797072

15. Berendes S, Heywood P, Oliver S, Garner P. Quality of Private and Public Ambulatory Health Care in Low and Middle Income Countries: Systematic Review of Comparative Studies. PLOS Medicine. 2011 Apr 12;8(4):e1000433.

16. Das J, Hammer J. Which doctor? Combining vignettes and item response to measure clinical competence. Journal of Development Economics. 2005;78(2):348-383.

17. Using the TDR Global Competency Framework for Clinical Research: A set of tools to help develop clinical researchers [Internet]. The Special Programme for Research and Training in Tropical Diseases; 2016 [cited 2019 Sep 19]. Available from: https://apps.who.int/iris/bitstream/handle/10665/250673/9789241511551eng.pdf;jsessionid=87377C00682EF7115295A87D531B6C5B? sequence=1

18. Alonge O, Rao A, Kalbarczyk A, Maher D, Gonzalez Marulanda ER, Sarker M, et al. Developing a framework of core competencies in implementation research for low/middle-income countries. BMJ Glob Health. 2019 Sep;4(5):e001747.

19. Calhoun JG, McElligott JE, Weist EM, Raczynski JM. Core Competencies for Doctoral Education in Public Health. Am J Public Health. 2012 Jan;102(1):22-9.

20. Calhoun JG, Ramiah K, Weist EM, Shortell SM. Development of a Core Competency Model for the Master of Public Health Degree. Am J Public Health. 2008 Sep;98(9):1598-607.

21. Calhoun JG, Davidson PL, Sinioris ME, Vincent ET, Griffith JR. Toward an understanding of competency identification and assessment in health care management. Quality management in health care. 2002;11(1):14-38.

22. Sharma K, Zodpey S, Gaidhane A, Syed ZQ, Kumar R, Morgan A. Designing the Framework for Competency-Based Master of Public Health Programs in India: Journal of Public Health Management and Practice. 2013;19(1):30-9.

23. Ministry of Health and Family Welfare, Government of India. MPH-Model Course Curriculum [Internet]. 2018. Available from: https://mohfw.gov.in/sites/default/files/MPH-Model\%20Course\%20Curriculum.pdf

24. Raghav P, Kumar D, Bhardwaj P. Experience of Delphi technique in the process of establishing consensus on core competencies. Int J App Basic Med Res. 2016;6(3):191.

25. Ministry of Health and Family Welfare, Government of India. Ayushman Bharat Health and Wellness Center. 2016.

26. Ministry of Health and Family Welfare G of I. National Health Policy 2017. 2017.

27. Turoff M, Linstone HA, editors. The Delphi Method: Techniques and Applications. 2002.

28. Nelms KR, Porter AL. EFTE: An interactive Delphi method. Technological Forecasting and Social Change. 1985 Aug;28(1):43-61.

29. Goodman CM. The Delphi technique: a critique. J Adv Nurs. 1987 Nov;12(6):729-34.

30. Public Health England, Public Health Wales, NHS Scotland, Public Health Agency of Northern Ireland. Public Health Skills and Knowledge Framework [Internet]. 2019. Available from:

https://assets.publishing.service.gov.uk/government/uploads/system/uploads/attachment_data/file/777278/PHSKF_subfunctions_explained.pdf

31. Pan American Health Organization. Core Competencies for Public Health-A Regional Framework for the Americas [Internet]. Available from: https://cursos.campusvirtualsp.org/pluginfile.php/72114/mod_label/intro/competenciasENG\%20final.pdf

Page 14/16 
32. Benavides FG, Moya C, Segura A, Lluïsa de la Puente M, Portaa M, Amela C. Las competencias profesionales en Salud Pública. Gaceta Sanitaria. 2006 May;20(3):239-43.

33. Public Health Association of New Zealand. Generic Competencies for Public Health in Aotearoa-New Zealand [Internet]. 2007. Available from: https://app.box.com/s/vpwqpz8yyus8d8umucjzbtdi1m111p5u

34. Centers for Disease Control and Prevention. A Collection of Competency Sets of Public Health-Related Occupations and Professions [Internet]. 2001. Available from:

http://www.phf.org/resourcestools/Documents/List_of_Competencies_Sets.pdf

35. Trevelyan EG, Robinson PN. Delphi methodology in health research: how to do it? European Journal of Integrative Medicine. 2015 Aug 1;7(4):423-8.

36. StataCorp. Stata Statistical Software. College Station, TX: StataCorp LP; 2016.

37. Gosselin D, Cooper S, Bonnstetter RJ, Bonnstetter BJ. Exploring the assessment of twenty-first century professional competencies of undergraduate students in environmental studies through a business-academic partnership. J Environ Stud Sci. 2013 Sep;3(3):359-68.

38. Bradley EH, Taylor LA, Cuellar CJ. Management Matters: A Leverage Point for Health Systems Strengthening in Global Health. Int J Health Policy Manag Int J Health Policy Manag. 2015;4(47):411-415.

39. Powell C. The Delphi technique: myths and realities. J Adv Nurs. 2003 Feb;41(4):376-82.

40. Williams PL, Webb C. The Delphi technique: a methodological discussion. Journal of Advanced Nursing. 1994;19(1):1806.

41. Diamond IR, Grant RC, Feldman BM, Pencharz PB, Ling SC, Moore AM, et al. Defining consensus: A systematic review recommends methodologic criteria for reporting of Delphi studies. Journal of Clinical Epidemiology. 2014 Apr;67(4):401-9.

42. Veras M, Pottie K, Welch V, Labonte R, Eslava-Schmalbach J, Borkhoff CM, et al. Reliability and Validity of a New Survey to Assess Global Health Competencies of Health Professionals. Global Journal of Health Science. 2012;5(1):13-27.

\section{Figures}


Step 2: Organization of consensus workshop: Background information discussed and questions about the background resolved

Twenty-two public health experts and government officials participated

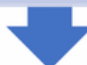

Step 3: Revision and addition to the initial list

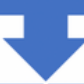

Step 4: Compilation of amendments and development of a modified list

14 new competencies added

54 competencies organized into 8 domains

Step 5: First Delphi scoring

All 22 participants rated each of the 54 statements on a Likert scale

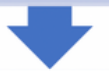

Step 6: Score compilation, analysis and summarization

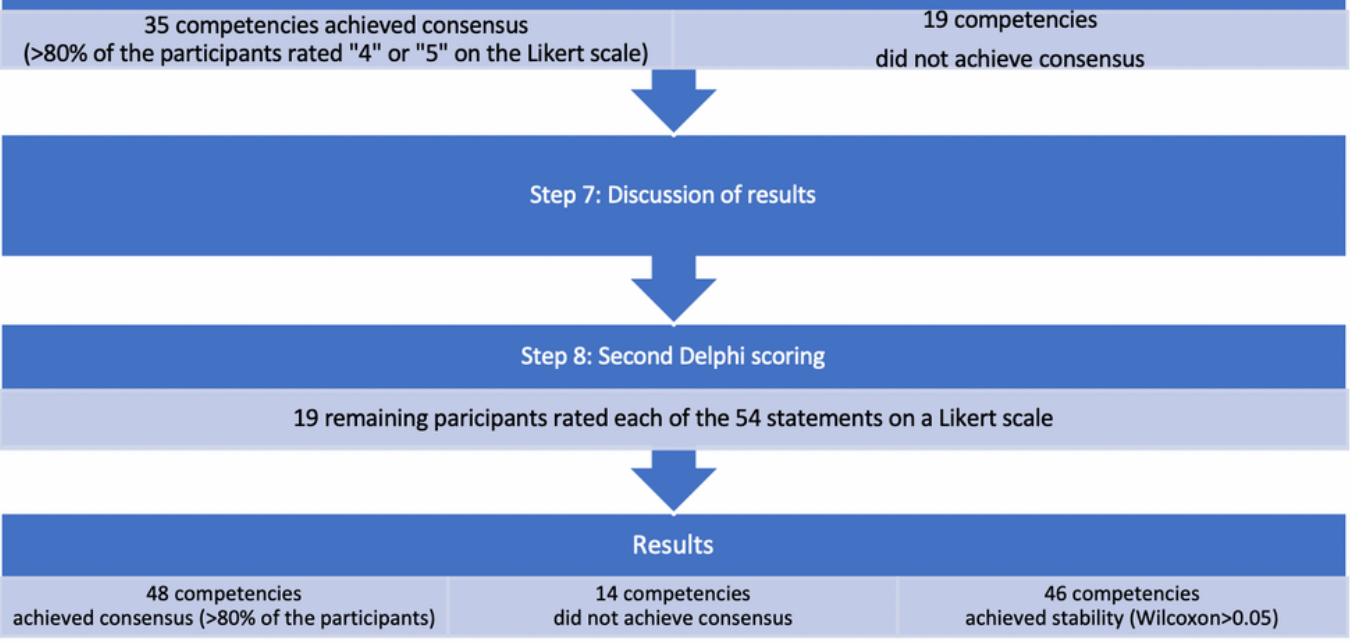

Figure 1

Step diagram of the process and results of identifying core competencies for public health professionals

\section{Supplementary Files}

This is a list of supplementary files associated with this preprint. Click to download.

- PublicationFilesadditionalfile1.docx 